\title{
EUA, NICARÁGUA E NOAM CHOMSKY
}

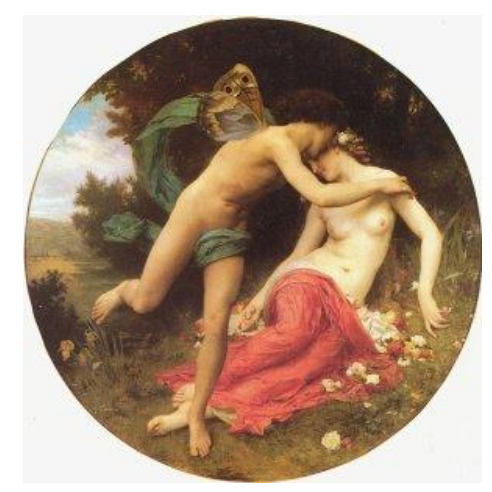

Michel Justamand

\section{Resumo}

$\mathrm{O}$ artigo que segue se propõe a debater, por meio da bibliografia de Noam Chomsky, a relação entre os Estados Unidos da América - EUA e a Nicarágua. Pretende resgatar a história do período compreendido entre os anos da década de 80 do século passado, em especial. Mas contextualizando a década de $80 \mathrm{com}$ alguns fatos relacionados da década anterior. Procuram-se mostrar nesses escritos que os EUA agiram contra o governo e a população nicaraguense com métodos militares e políticos similares aos usados pelo regime nazista, no período da II Guerra Mundial.

Palavras-chave: Nicarágua, EUA, Chomsky.

\begin{abstract}
The article that follows sets out to discuss, through the bibliography of Noam Chomsky, the relationship between the United States of America-United States and Nicaragua. Revisits the story of the period between the years of the last century, 80 in particular. But contextualizing the 80 with some related facts of the previous decade. Seeking to show in those writings that the United States acted against the Government and the Nicaraguan population with military and political methods similar to those used by the Nazi regime, in the period of World War II.
\end{abstract}

Keywords: Nicaragua, USA, Chomsky.

\section{Introdução}

Almeja-se, nestes escritos, exibir algumas memórias da revolução nicaraguense, a invasão, suas consequências e também a política externa dos Estados Unidos da América (EUA), o império invasor. Aspira-se dialogar com alguns dos atores da revolução, como os insurgentes 
sandinistas, os contras, o governo de Ronald Reagan, a população em geral e os indígenas envolvidos nessas investidas do grande capital em terras já muito destruídas pelos conquistadores anteriores. Tal diálogo realizar-se-á por meio dos textos (livros autorais, artigos em coletâneas e entrevistas concedidas aos mais diferentes meios de comunicação) de Noam Chomsky, que é um dos maiores comentadores críticos das políticas externas (sejam elas econômicas, sociais, militares e ou culturais) dos EUA, com suas obras e artigos que contestam as ações estadunidenses e que são de enorme reconhecimento internacional por seus conteúdos contundentes (JUSTAMAND, março de 2014/ fevereiro de 2015).

Articulista notório e célebre internacionalmente por voltar seus interesses intelectuais a apresentar verdades a respeito dos projetos estadunidenses para o mundo. Sempre disposto a conceder entrevistas a todas as formas midiáticas e a todos os países, onde relata as desmedidas dos governos dos EUA. Entre as muitas entrevistas, uma delas, é a de 22 de setembro de 2001 para o jornal Folha de São Paulo, em que Chomsky trata, entre outros assuntos, do caso da Nicarágua. Lembra que os EUA foram considerados culpados por uso ilegal da força nesse país centro-americano (IDEM).

Desde os anos 1960 do século passado, Chomsky se dispõe a informar àqueles que desejarem a respeito da ameaça que é a política externa dos EUA para o mundo. Faz isso apresentando detalhes desse projeto astuto, independentemente de momentos históricos de grandes conturbações mundiais, como os da Guerra Fria, por exemplo. Ou das relações internacionais em que os EUA tentam, e na maioria das vezes conseguem, impor seus interesses sobre países vulneráveis.

Pretende-se ainda, com esse artigo, mostrar que é possível contrapor o império "nazista" atual, como lembra Chomsky, por diversas vezes em escritos e entrevistas, nas instituições internacionais, como a Organização das Nações Unidas (ONU). Em O Império Americano: hegemonia 
on sobrevivência faz diversas comparações dos atos políticos nacionais e internacionais dos EUA com os da Alemanha nazista, entre os anos de 1933 a 1945 (CHOMSKY, 2004, p. 72 e 75). Também compara a medida antiterror dos EUA com ações dos nazistas (CHOMSKY, 1996a, p. 116). Salienta as relações amigáveis entre os governos dos EUA e os nazistas, no período anterior a entrada estadunidense na Segunda Guerra Mundial, oficialmente em 1941. Expõe também que muitas empresas do país anglosaxão, na América do Norte, tinham interesse direto na máquina de guerra construída pelos nazistas (IDEM).

Para tanto, esses escritos estão divididos em: 1 - Antecedentes Históricos; 2 - Por que as garras do Império recaíram sobre a Nicarágua?; 3 - Quem vai pagar por isso?; 4 - Exemplos a serem seguidos por todos (considerações finais).

\section{Antecedentes Históricos: algumas memórias}

Noam Chomsky conta que, desde a fundação da Nação estadunidense, esquadrinham-se formas de manipular as mentes da maioria da população, para, entre outros propósitos, esconder a sua própria História. Assim, tenta-se arregimentar mentes, como os exércitos fazem com os corpos, sempre em consonância com a ideia de que é essencial para o regime democrático, do qual os EUA são os principais mantenedores e divulgadores (JUSTAMAND, março de 2014/ fevereiro de 2015). Chomsky não deixa de sublinhar que o principal promotor da Convenção Constitucional, James Madison, proferiu em seus discursos que é de responsabilidade do governo proteger os interesses da minoria dos abastados contra a maioria. De qualquer forma, Madison, como era astuto, reconheceu que esse aspecto (CHOMSKY, 1996a, p. 57) governamental seria um problema para a recém-criada democracia americana, como para qualquer outra o é (CHOMSKY, s/data, p. 13). 
A Nicarágua tem um caso em particular com os EUA que remonta ao século XIX. Já em 1854, os Estados Unidos, com sua marinha, destruíram uma cidade costeira nicaraguense. E o motivo que na época justificou tal vingança foi um alegado insulto feito aos oficiais do "império do medo (EUA)" e também ao milionário estadunidense Cornelius Vanderbilt. Assim, afirma Chomsky, torturar a Nicarágua é um ritual antigo (CHOMSKY, 1996a, p. 172). Em nome da promoção da democracia no continente americano, já no início do século passado, os EUA promoveram uma série de intervenções militares na América Central, entre elas está o caso da Nicarágua. As intervenções tinham ainda como objetivos o Haiti e a Guatemala (CHOMSKY, 2009, p. 174).

A Nicarágua foi alvo dos EUA no amanhecer do século XX (CHOMSKY, 1998, p. 82). A ocupação no país centro-americano ocorreu durante todo o século XX: os EUA, baseando-se em tratados, arrogam-se o direito de construírem um canal no Panamá, com o fim lógico de impedir qualquer concorrente na região. Mas um tratado como esse, assinado no momento de ocupação militar do país, não pode ter valor, ainda mais quando o país que o assinou é o mesmo que levará vantagens. E esse tratado garantia direitos perpétuos aos EUA, nada mais injusto para com toda a população nicaraguense e, sem dúvidas, um abuso comercial e social (CHOMSKY, 1996a, p. 63).

A Guerra Fria foi mote de discussões e testes para dois grandes Impérios formados durante o século XX, EUA e URSS. A duração desse período é de 1945 até a queda do muro de Berlim, em 1989, vinculada ao colapso das políticas de dominação soviéticas em seus espaços permitidos e acordados com os EUA. Assim, para a URSS, era uma guerra contra os seus satélites e, para os EUA, contra todo o terceiro mundo (CHOMSKY, 2007a, p. 45). É importante que esses fatos fiquem claros e as intenções desses impérios também. A clareza se faz importante ainda por que, tanto no caso dos EUA, quanto da URSS, a Guerra Fria serviu para consolidar e 
manter sistemas de privilégios e coerção no âmbito, especialmente, nacional (IDEM, p. 49).

A população em cada um desses Estados aceitava as imposições em virtude das coações, que consistiam em usar a imagem de um inimigo maléfico: por meio da mídia, um dizia que o inimigo maléfico era o outro, justificando assim gastos com armamentos e investimentos em guerras contra todos, especialmente os mais fracos no âmbito militar (IDEM, p. 51). Para o autor, esta guerra fria, que na verdade foi muito quente, persistiu enquanto teve utilidade funcional para os administradores de ambas as partes (IDEM, 45) e também enquanto foi muito atraente política e economicamente para ambos os Impérios do medo do século XX (CHOMSKY, 2003b, p. 46). O caso da Nicarágua se encaixa no terceiro mundo, ou seja, área de intensificação, utilidade funcional e atração econômica da guerra por parte dos EUA.

O que mais nos comove é que no período da maior ditadura terrorista da Nicarágua, a de Anastácio Somoza Debayle, houve um terremoto que devastou o país, em 1972. Na ocasião, o governo dos EUA enviou substancial ajuda humanitária. Entretanto, em 1988, sob o governo sandinista, houve outro desastre natural, um vulcão que também abalou o país, e nem um dinheiro foi endereçado para esse país vindo dos EUA (CHOMSKY, 1993, p. 211). Isso porque o medo dos EUA é que talvez esse mísero centavo fosse parar nas mãos dos sandinistas que fariam usos errados do dinheiro, ou seja, investir em melhorias das condições sociais da população de modo geral.

É curioso que, enquanto durou na Nicarágua a ditadura tirânica de Somoza (CHOMSKY, 2005a, p. 44-5), ela foi promovida, mantida e abastecida pelos EUA, leia-se pelo governo Jimmy Carter. O autor acentua que durante esse governo houve a tentativa frustrada de manter o poder em mãos de alguém que fosse "aliado" a interesses anglo-saxões, com uma mediação. Mas para insatisfação estadunidense foi tarde demais: os 
sandinistas conseguiram derrubar Somoza e sua Guarda Nacional (CHOMSKY, 2007b, p. 34; 1998, p. 52). Não houve problemas, nem muito menos qualquer tipo de preocupações por parte do governo do país da América do Norte com a vida dos milhares de mortos entre os nicaraguenses (CHOMSKY, 1996a, p. 257).

A Guarda Nacional representava um estilo de proteção dos interesses estadunidenses. Era um exército digno, segundo a avaliação dos anglo-saxões. Um exército que funcionaria no momento em que a polícia e os militares não pudessem mais ser controlados na Nicarágua. Esse funcionamento seria, evidentemente, em nome de se garantir um regime político submisso aos desígnios dos EUA (CHOMSKY, 2003b, p. 72). Tinha como função, nesse período pré-revolução dos sandinistas, manterem todos calados, mesmo que fosse à custa de muitas mortes em beneficio dos interesses dos grandes empresários do "país irmão poderoso do norte". Essa guarda especial sempre foi brutal e sádica (IDEM, p. 44), responsável, inclusive, por atrocidades contra os sandinistas até 1979, responsável pelas mortes de dezenas de milhares de pessoas e destruído aldeias inteiras por serem apenas suspeitas de darem guarida aos guerrilheiros sandinistas. Ainda existem as recordações dos moradores destas aldeias de que houve também bombardeios aéreos, torturas terríveis e execuções sumárias (CHOMSKY, 2007b, p. 207).

Para completar o mal-estar causado pelos representantes dos estadunidenses na Nicarágua, o próprio embaixador dos EUA no período, por incrível que pareça, ainda falou a favor de tais atrocidades contra a população nicaraguense cometida pela Guarda Nacional, mesmo após a queda de Somoza. Alguns ainda acreditavam que, na Nicarágua, haveria um somozismo sem Somoza (CHOMSKY, 1996b, p. 52-3). Mas, de toda forma, a Guarda Nacional e a ditadura de Somoza, apoiada pelos EUA, foram derrubadas. O fato era, então, saber como manter um sonho: o sonho de tentar dar um rumo diverso para o que vinha ocorrendo na 
Nicarágua, sob o signo dos rebeldes sandinistas. Uma alternativa que promoveu uma nova vitalidade e a esperança entre o povo nicaraguense (CHOMSKY, 2004, p. 15).

\section{Por que as agressões do Império incidiram sobre a Nicarágua?}

Devia-se perguntar, na verdade, por que os EUA foram tão longe nas atrocidades, imposições e controles, na Nicarágua. Esses atos se devem em parte às conquistas dos sandinistas no período posterior à tomada de poder em 1979. Os ditos rebeldes sandinistas conseguiram em pouco tempo melhorar as condições de vida do povo, estimular sua participação efetiva nos processos de desenvolvimento, buscaram também resolver as injustiças da posse da terra e ainda estender os serviços agrícolas, médicos, hospitalares e educacionais a todas as famílias camponesas (CHOMSKY, 1996b, p. 54). Ou seja, os sandinistas melhoraram as condições de vida de todos os moradores mais necessitados do país (JUSTAMAND, março de 2014/fevereiro de 2015).

Eles ainda desenvolveram programas educacionais que incrementavam enormemente a alfabetização. Tinham também programas de saúde que visavam à redução da mortalidade infantil e tinham como perspectiva o aumento da longevidade de seus compatriotas. Ganharam prêmio por seus programas de saúde da Organização Mundial de Saúde (OMS) pelos êxitos nesse campo. Também foram muito bem-sucedidos no programa de Reforma Agrária, que funcionou (CHOMSKY, 1998, p. 77). Assim, eles, os sandinistas, estariam roubando as matérias-primas que são, para os EUA, suas posses na Nicarágua e distribuindo aos seus pobres e necessitados (IDEM, p. 78). Um exemplo a ser abolido e totalmente indesejável no quintal do seu próprio domicílio, que é como os governos estadunidenses entendem a região compreendida pelos países centro americana (JUSTAMAND, março de 2014/fevereiro de 2015). 
Para completar, no início dos anos 80, o Banco Mundial considerou alguns setores da Nicarágua extraordinariamente bem sucedidos. Aliás, mais do que em qualquer parte do mundo. E o Banco Interamericano de Desenvolvimento concluiu que a Nicarágua tinha tido notáveis avanços no setor social e estava lançando as bases para um desenvolvimento socioeconômico em longo prazo (CHOMSKY, 1996b, p. 54; 2005a, p. 46). Isso tudo estabelece um conflito com os interesses dos EUA na região e no mundo, porque os estadunidenses não querem o melhor para os pobres dos outros países, pois a melhoria de vida para os pobres poderia gerar convulsões sociais onde não existam tais benefícios (JUSTAMAND, março de 2014/ fevereiro de 2015).

$\mathrm{O}$ autor acrescenta que, pela primeira vez, a Nicarágua tinha um governo que se interessava pelo povo. Os sandinistas procuraram dirigir os recursos agrícolas aos pobres. $\mathrm{E}$ foram bem sucedidos nessa tentativa. Algo, como sugere Chomsky, maravilhoso de se observar. Isso provocava ódio nos estrategistas dos governos dos EUA, como George Shultze e Alan Cranston (CHOMSKY, 2005a, p. 47 e 55). Quando um país começa a destinar seus próprios recursos à sua população deve ser destruído pelos EUA (CHOMSKY, 1998, p. 95), segundo a ideologia da "águia” ou do império nazista, como denomina Chomsky. Ainda mais se esse país já estava sob a esfera de interferência dos EUA, como era o caso da Nicarágua (JUSTAMAND, março de 2014/fevereiro de 2015).

Existe, nos EUA, uma ideia de que os países fora do domínio político podem ser, de alguma forma, exemplos a não ser seguidos por outros, por fazerem o que não devem ser feito. Melhorias para os mais pobres dentro de suas próprias fronteiras nacionais. E a Nicarágua seria um desses para os países centro americanos onde, evidentemente, há certa “pax romana" imperial, ou seja, onde os desejos, imposições e decisões dos EUA eram mantidas, até a revolução sandinista. Ou ainda serviria de exemplo para outros países do mundo, o que não pode de forma alguma ocorrer. $\mathrm{E}$ 
seria um abuso frente aos interesses do Império. Os argutos pensadores estadunidenses chamam isso de efeito dominó (CHOMSKY, 2009, p. 138). Esse efeito era preciso deter, eles estão dispostos a fazer isso com as garras da águia, representados pelos soldados, imposições, controle econômico, político e social, sabotagens, entre outros meios (JUSTAMAND, março de 2014/fevereiro de 2015).

Para solucionar esses "mal-entendidos" sociopolíticos e econômicos gerados pelos sandinistas no poder na Nicarágua, foi preciso tomar uma postura radical. Assim, o presidente "eleito democraticamente" nos EUA, Ronald Reagan, em 1981, tomou as devidas providências para garantir os interesses dos seus financiadores. Ou seja, iniciou uma luta armada sem precedentes contra um país completamente indefeso, e sem justificativas plausíveis, apesar de que não acreditamos em nenhum motivo para se realizar uma guerra. Partia-se de uma ofensiva ideológica que inventava um monstro imaginário: a possibilidade da invasão dos EUA pela Nicarágua, e depois se realizou uma campanha propagandística na mídia vendida para "esmagar" esse país (CHOMSKY, 2003c, p. 39). Dizia-se que a Nicarágua, com suas hordas de terroristas e subversivos, chegaria ao Texas/EUA em cerca de dois dias de estrada (CHOMSKY, 2005b, p. 95) visando, evidentemente, a invasão do território dos EUA.

Reagan chamou de estado de emergência nacional (CHOMSKY, 2002a, p. 46) ao reagir frente à Nicarágua. Esse pequeno país passou a ser considerado ameaça extraordinária à segurança dos EUA. Segundo Chomsky, são os pequenos países que representam as maiores ameaças para a política exterior do império americano. Já para a questão da ameaça a segurança nacional, é algo ridículo de se discutir em se tratando de Nicarágua invadir o território estadunidense. Isso por que, como está previsto dentro dos interesses dos governos dos Estados Unidos da América, as matérias-primas contidas nesses países pequenos e indefesos devem sem dúvidas pertencer sob os interesses do grande irmão do norte 
do continente. Especialmente as matérias-primas da América Latina. Assim, quanto menor é o país e maior é sua vitória na adversidade, maior será a expressão que assume o resultado. Esse exemplo, para os outros países, tem que ser escondido, esquecido e não divulgado nos anais da História Mundial, muito menos pelos interesses dos governos estadunidenses que, logicamente, vão de encontro com essa vitória na adversidade (CHOMSKY, 1998, p. 75-6).

Com as desculpas de que a Nicarágua se envolveria com a compra de armas dos Russos (CHOMSKY, 1998, p. 72) e com o terrorismo internacional (CHOMSKY, 2007b, p. 76), os EUA também clamavam a toda sua população para entender os objetivos dos futuros ataques. Mas sem saberem que os nicaraguenses foram levados a procurar o outro lado do mundo, ou seja, a URSS, graças às políticas externas dos EUA que lhes impunha o embargo de alimentos, remédios e armas de seus aliados para a Nicarágua. Ficando sem comida, sem remédios e sem armas para se proteger o que sobrou foi procurar aliados fora do espectro local. Isso justificava a invasão do país centro americano pelo império nazista dos EUA.

Outro motivo para a invasão, dada por Reagan era que os líbios gostariam de ter a Nicarágua como seu posto avançado de venda de armas, interpreta Chomsky (MITCHELL e SCHOEFFEL, 2005, p. 119). Algo que está totalmente fora de lugar na História. Nunca ocorreu. Mas evidentemente serve de argumento para a população e especialmente para se conseguir recursos maiores no congresso dos EUA, recursos em abundância, aliás, porque são recursos públicos.

\section{3. É preciso impedir a reprodução do "mau exemplo"}

Existe um discurso governamental dos EUA abordando questões que são controversas para os interesses imperiais estadunidenses. Interesses 
que vão além da justiça, da liberdade de escolha, dos direitos humanos e ou da soberania nacional de cada país pelo mundo (Cuba, Irã, Afeganistão, Guatemala, Indonésia, Venezuela) e em especial, claro, da Nicarágua (CHOMSKY, 2003b, p. 28).

Há também um discurso dos seguidos governos dos EUA durante os anos 60, 70 e 80, (e até os dias de hoje, claro), de que é preciso colocar ordem nos desordeiros. Aqueles que não cumprem os devidos papéis que lhes são designados. Ou seja, países que resolveram caminhar com suas próprias "pernas”, ter liberdade e promover a mudança e a justiça social, como é o caso, dentre outros, da Nicarágua dos anos 80 (CHOMSKY, 2003b, p. 48).

Os dados utilizados, por esse mesmo autor, demonstram que se podiam controlar os militares dos países ditos aliados e que se não fosse possível tal controle, as garras afiadas da águia entraram em ação, derrubarse-iam os governos a qualquer custo. Mesmo que causassem a morte de muitos, deslocamentos humanos desnecessários, feridos aos milhões (CHOMSKY, 1976, p. 125-51), etc. Realizar-se-iam então pós-queda do regime a reconstrução de exército digno, ou seja, submisso aos interesses dos governos estadunidenses (CHOMSKY, 2003b, p. 72).

Assim, em nome de impedir o aparecimento de um mau exemplo no seu quintal, como seria o caso da Nicarágua, era preciso impedir. Isso se deu por meio de esforços "extraordinários” para os EUA, como devastar todo o país, com terrorismo social e econômico, recusa de oferecer ajuda para casos de catástrofes naturais, algo que era feito em outros momentos, quando existia um governo nicaraguense mais submisso aos interesses imperiais da Águia (IDEM, p. 79). Ou seja, direitos humanos somente quando os humanos daquele local fossem nossos aliados, submetidos, submissos, dependentes e (ou) nossos párias (JUSTAMAND, março de 2014/ fevereiro de 2015). 
Lembrando sempre que pessoas sem importância existem, segundo as dissipações da imprensa estadunidense, que são "entregues" aos interesses dos mega empresários e suas corporações. Esses que atuam intensamente para que todos os recantos do mundo se tornem consumidores de seus produtos, mesmo que não sejam úteis e nem lhes sirvam para nada onde moram. Dessa forma, lembra Chomsky (2003b, p. 97), imagens de corpos torturados, mutilados e bebês morrendo em vários locais do mundo, por força de tais interesses financeiros, são dissimulados pela imprensa como sendo de pessoas sem importância para o sistema. Algo que, completamente somos contra. A mídia deveria mostrar a realidade. Deveria apresentar e discutir com profundidade teórica e técnica os fatos, não esconder, dissimular, disfarçar e proteger com essas ações alguns poucos dentro do sistema mundo (JUSTAMAND, março de 2014/fevereiro de 2015).

Infelizmente para o governo dos EUA o governo sandinista rebelde dos anos 80 da Nicarágua cometeu fortes heresias ao possibilitar melhores condições de vida para uma parcela maior da população. Por exemplo, usando os próprios recursos naturais em beneficio dos habitantes locais. Ou ainda, patrocinando um tipo de desenvolvimento independente dos EUA (CHOMSKY, 1998, p. 79). E por ter cometido tais heresias deveria pagar. As garras foram mostradas, nesse caso, com os embargos econômicos. Esse tipo de ação foi feito simplesmente para que ocorresse a dissidência interna e gerasse a desconfiança e a luta entre os próprios nicaraguenses. Forçando, pós-embargo, que os sandinistas corressem para pedir apoio aos russos. Como já fora lembrado no subitem anterior. Tal atitude dos próprios habitantes do país justificaria a busca para derrubar o regime revolucionário sandinista da Nicarágua. Afinal, as benesses sociais conquistadas pelas pessoas mais pobres não podem servir de exemplo para outros países pobres no mundo. Eles têm que ser destruídos. Eram a laranja podre do período. 
Na entrevista que Chomsky concede a Heinz Dieterich, fala sobre as questões envolvendo os EUA e a América Latina como um todo. Cita em pormenores alguns dos países de nostra América, como apontado acima em um dos trechos do interview, comenta sobre a Nicarágua, alvo de nossas interferências nesse artigo. Em outro momento desse encontro, Chomsky diz que a História do envolvimento dos EUA com a América Latina tem o objetivo de destruir os movimentos populares. Esse envolvimento não tem a menor preocupação humanitária. Deveria sim reprimir qualquer intenção de independência, como foi feito. E tendo por objetivos inequívocos implantar ditaduras brutais e repressivas, que são suscetíveis de se lidar, pois com essas formas de se realizar política se mantêm toda a região sob o julgo do governo mais ao norte do continente americano (IDEM, p. 81).

Chomsky recorre à memória e as lembranças da própria História da construção da política e da suposta democracia nos EUA. Quando salienta que entre o final do século XVIII e início do XIX as discussões levaram ao que foi, finalmente, formulada pelo presidente do Congresso Constituinte à época, em meio às reflexões se os EUA seriam uma democracia e (ou) teriam outro regime político. Esse presidente do congresso formulou a seguinte perspectiva social de que o país deveria ser governado pelos seus proprietários (IDEM, p. 95), ou seja, quem tem posses é que deve governar, segundo seus interesses, a política interna e externa do país. E infelizmente é o que tem ocorrido desde então com a maior potência militar da História da Humanidade.

Os EUA, desde então, têm agido em defesa dos seus interesses privados e dos proprietários de mega corporações pelo mundo. Matando, espoliando, controlando, impondo, retaliando, desobedecendo, impondo, etc., seus desejos, ditos democráticos, de justiça, de liberdade e de soberania, entre outros, pelo mundo. Desse modo, claramente, é instituído pelos governos sucessivos dos EUA a seguinte aferição: permita-nos que 
"roubemos", tomemos posse, de tudo de vocês sempre que quisermos e (ou) desejarmos que nos interesse (JUSTAMAND, março de 2014/fevereiro de 2015).

Já em entrevista concedida a David Barsamian, publicada no livro: Segredos e mentiras, Chomsky lembra o que ocorreu pós-embargos dos EUA sobre a Nicarágua. Trata da questão dos índios, em especial, que a imposição do embargo econômico foi responsável por uma enorme mortandade deles (CHOMSKY, 1999b, p. 104). Sem a publicação de nenhuma palavra nos jornais dos EUA, ao contrário do que ocorria durante a década de 80 quando atacavam o perigoso inimigo, a Nicarágua. Como dizia Reagan a dois dias de marcha do Texas (CHOMSKY, 2003a, p. 29), loucura total, algo impensável. Quando o exército nicaraguense teria condições de entrar nos EUA, passando pelo México? Até o presidente mexicano, à época, deu risada de tamanha insanidade discursiva de oratória e de retórica de Ronald Reagan.

Infelizmente, a Nicarágua, graças a essas ações dos EUA, transformou-se num centro importante para os transbordos de drogas. Com epidemias de uso de narcóticos por vasta parte da população. Incentiva-se o uso de cocaína entre os índios para se trabalhar mais, visto que caíram em dependência econômica demasiada. Mas como ninguém mais se importa com esses índios, que teriam ajudado a derrubar o regime sandinista, agora não têm nenhum valor. Não importam as condições de trabalho em que estão submetidos. Caso morram são trocados imediatamente. Algo natural dentro do chamado "livre mercado" (CHOMSKY, 1999b, p. 105).

Em seu livro "Poder e Terrorismo", outra publicação baseada em entrevistas, Chomsky aponta que os mesmos "astros" que atuavam na década de 80 durante todas as atrocidades cometidas pelos EUA pelo mundo, ainda atuam. Como é o caso de John Negroponte. Ele era embaixador em Honduras nos anos 80. Lá era à base de operações 
terroristas dos EUA contra a Nicarágua. E até 2003, no mínimo, Negroponte era com certeza o responsável pela Guerra contra o terrorismo nomeado pela ONU como embaixador para conduzir essa ação internacional. $\mathrm{O}$ autor reflete que se são as mesmas pessoas, as mesmas instituições e, as mesmas políticas, logo os resultados serão os mesmos (CHOMSKY, 2005c, p. 74). As garras da Águia continuam a ser sentidas por todas as partes da Terra, como: no Irã, no Afeganistão, na Síria, na Coréia do Norte, na Líbia, em Cuba ainda, por incrível que isso possa parecer, mesmo depois de anos de embargo e boicotes de todas as ordens contra esse país. Com embargos, guerras de conquista, imposições, vendas de armas, e outras medidas contra a soberania desses países e de outros tantos.

Chomsky dedica parte de sua produção e analises reflexivas ao que é publicado pela grande mídia dos EUA. Essas análises frequentemente aparecem em seus comentários sobre os países da América Latina. E numa dessas, trata da política externa estadunidense desde a II Guerra Mundial. Ali aborda a questão da Nicarágua. Lembra que houve ataques a alvos indefesos feitos pelos contras, grupos organizados e armados pelos EUA dentro das fronteiras nicaraguenses. E salienta que os jornais estadunidenses apresentavam esses fatos como naturais para que os sandinistas desviassem seus escassos recursos, que eram aplicados a políticas sociais, para a guerra contra os protegidos dos EUA (CHOMSKY, 2005a, p. 48). Isso faria com a que população, segundo os teóricos do governo imperial, ficasse contra os sandinistas nas eleições nacionais. Mas qual foi à surpresa, os sandinistas, mesmo com todas as dificuldades impostas pelo império nazista dos EUA, receberam 40 por cento dos votos. Uma vitória dos revolucionários contra o regime imperial (IDEM, p. $50)$.

Em outra das suas publicações sobre a mídia, relata que nos EUA, a Nicarágua era vista pela mídia vendida ao sistema, como um monstro. 
Aponta que isso é uma ofensiva claramente ideológica inventando uma monstruosidade para o imaginário popular para depois poder destruí-lo (CHOMSKY, 2003c, p. 39). Mesmo procedimento com diversos outros países ainda hoje pelo mundo, vide: Coréia do Norte, Afeganistão, Iraque, etc.

\section{Quem pagará por isso?}

Os ataques sistemáticos promovidos pelos EUA durante os anos de 80 na Nicarágua levaram à morte dezenas de milhares de pessoas, além de ter promovido também o desabrigar de outras tantas pessoas e, por final, ter contribuído para a destruição do país (CHOMSKY, 2005c, p. 2). Lembremos, ainda, que essa situação de atacado colocou o país em uma situação que dificilmente conseguirá retornar, ou seja, nunca mais será como fora na época dos sandinistas.

Para derrubar a política sandinista que estava agradando aos nicaraguenses, foi preciso criar todo tipo de ameaças, cortes, investimentos em armas e em terroristas de Estado, com a ajuda dos chamados de os Contras, e, por último, apontar a "arma" na cabeça da população na hora do voto. Ou seja, ameaçar de que, caso não votassem no candidato dos EUA, os embargos econômicos, políticos, sociais e militares continuariam. Assim, em nome de não passar fome e nem de sofrer com a falta generalizada de remédios e outros bens, a população votou democrática e "livremente" nos candidatos dos EUA (CHOMSKY, 1996a, p. 242).

$\mathrm{Na}$ Nicarágua o resultado não poderia ter sido pior. O desastre econômico que se seguiu ao fim do período dos sandinistas promoveu a criação de uma minoria privilegiada em detrimento de todos os outros voltarem a viver em péssimas condições, como na época de Somoza. Período em que as garras da águia não precisavam se mostrar e nem serem usadas (JUSTAMAND, março de 2014/fevereiro de 2015). 
Infelizmente, depois da destruição do projeto social, cultural e econômico dos sandinistas na Nicarágua, esse país se encontra entre os mais pobres do hemisfério, ficando antes apenas do Haiti. Nessas condições, grande parte da população se vê obrigada a tentar outros mecanismos de luta pela vida. Alguns se entregam para os piores abusos do sistema ou para os grandes empregadores de pobres, ou seja, o narcotráfico. É assim que a Nicarágua tem em suas cidades grandes, como Manágua, um corredor para a transferência da cocaína para os Estados Unidos. O consumo de drogas aumentou significativamente pós-governo queda do sandinista. Reflexos sem dúvidas das políticas aplicadas na Nicarágua posteriores à implantação de governos pró-EUA (CHOMSKY, 1993, p. 126).

\section{Exemplos a serem seguidos por todos (ou considerações finais)}

Noam Chomsky, quando de sua estada no Fórum Social Mundial de Porto Alegre, em 2003 indicou que, para enfrentarmos o império, é preciso ter vontade, aliás, muita vontade de fazer um mundo diferente. Um mundo que não seja baseado na violência e nem na submissão, muito menos no ódio e no medo (CHOMSKY, 2003a, p. 9). Acreditamos que um mundo onde caibam vários mundos seja a saída, conforme almejam os Zapatistas (EZLN - Exército Zapatista de Libertação Nacional. É um movimento de luta por um mundo melhor, mais digno e livre das amarras dos impérios capitalistas), do sudoeste do México (JUSTAMAND e MENDES, 2012, p. 131). Esse mundo onde caibam vários mundos é onde todos teriam direito a sua memória, aos seus espaços, mas também a voz e vez. É onde caminharíamos juntos e misturados todos os grupos humanos do mundo. Todos tendo direito a suas histórias, lembranças, memórias, as suas formas de alteridade cultural e social. E também suas reivindicações justas (IDEM, p. 14). 
A Nicarágua, sempre em busca dos meios pacíficos e internacionais para a resolução de suas problemáticas com os EUA, é um exemplo de luta contra o império (CHOMSKY, 1996a, p. 275) e também de espaço para uma vida digna, íntegra e com esperança. O autor afirma frequentemente que apenas a pressão popular pode fazer a diferença. Somente ela pode fazer frear as intenções e as intervenções militares dos EUA pelo mundo (CHOMSKY, 1993, p. 53). Propõe também estimular as pessoas de todos os locais do mundo, já se foi conquistado muito com isso. Fala também em formas de resistência interna contra os ataques dos EUA ou movimentos de solidariedade. E, sempre que possível, tentar conscientizar um grupo contra o racismo, seja de que tipo for: contra índios, negros, de gênero, religioso, étnico, social, cultural, geográfico (CHOMSKY, 1998, p. 130). Somente a luta de todos em tempo integral poderá ajudar a mudar essa situação (JUSTAMAND, 2010, p. 58).

\section{Referências}

CHOMSKY, N. 11 de setembro. Tradução de Luiz Antonio Aguiar. Rio de Janeiro: Bertrand Brasil, 2002-a.

- A política externa dos Estados Unidos da segunda guerra mundial a 2002. Tradução de Paulo Alves de Lima Filho. São Paulo: Movimento Consulta Popular, 2005-a.

- Ambições Imperiais. O mundo pós-11/09 em entrevista para David Barsamian. Tradução de C. E. de Andrade. Rio de Janeiro: Ediouro, 2005b.

Ano 501. A conquista continua. Tradução de Maria Cristina Guimarães. São Paulo: Scritta Editorial, 1993.

Como enfrentar o Império? In: CHOMSKY, N.; ROY, A.; AMIN, S. A ofensiva do Império e os dilemas da humanidade. São Paulo: Movimento Consulta Popular, 2003-a.

Contendo a democracia. Tradução de Vera Ribeiro. Rio de Janeiro/São Paulo: Record, 2003-b. 
- Controle da Mídia. Os espetaculares feitos da propaganda. Tradução de Antônio Augusto Fontes. Rio de Janeiro: Graphia, 2003-c.

. Entrevista concedida ao Jornal Folha de São Paulo, 22/09/2001.

- Estados fracassados: o absurdo do poder e o ataque à democracia. Tradução de Pedro Jorgensen Jr. Rio de Janeiro: Bertrand Brasil, 2009.

- Neoliberalismo e ordem global. Crítica do lucro. Tradução de António Cruz Belo. Lisboa: Editorial Notícias, 1999-a.

- Novas e velhas ordens mundiais. Tradução de Paulo Roberto Coutinho. São Paulo: Scritta, 1996-a.

- O governo do futuro. Tradução de Maira Parula. Rio de Janeiro/São Paulo: Record, 2007-a.

- O império americano: hegemonia ou sobrevivência. Tradução de Regina Lira. Rio de Janeiro: Elsevier, 2004.

- O novo Humanismo Militar: lições de Kosovo. Tradução de Jorge Almeida e Pinho. Porto: Campo das Letras, 2002-b.

O que o Tio Sam realmente quer? Tradução de Sistílio Testa e Mariúchka Santarrita. Brasília: UNB, 1996-b.

Poder e terrorismo: entrevistas e conferências pós-11 de setembro. Tradução de Vera Ribeiro. Rio de Janeiro/São Paulo: Record, 2005-c.

- Propaganda ideológica e controle do juízo público. Tradução de Danielle Mendes Sales. Rio de Janeiro: Achiamé, s/data.

- Rumo a uma nova guerra fria: politica externa dos EUA, do Vietnã a Reagan. Tradução de Clóvis Marques. Rio de Janeiro/São Paulo: Record, 2007-b.

- Segredos mentiras e democracia. Tradução de Alberigo Loutron. Brasília: UNB, 1999-b.

Um olhar sobre a América Latina. Entrevistas com Heinz Dieterich. Tradução de Luiz Ricardo leitão com a colaboração de Alberto Moby. Rio de Janeiro: Oficina do Autor, 1998. 
\& HERNAN, Edward S. Banhos de sangue. Tradução de Maria do Carmo Pizarro. São Paulo/Rio de Janeiro: 1976.

JUSTAMAND, Michel. Neoliberalismo: a máscara atual do capital. Rio de Janeiro: Achiamé, 2010.

JUSTAMAND, Michel. A águia e suas garras: EUA, Chomsky e Nicarágua. Ariadna Tucma Revista Latino-Americana, n. 9, mar 2014/fev 2015, vol. II.

JUSTAMAND, Michel e MENDES, Lilian Marta Grisolio. História e representações: cultura, política e gênero. Rio de Janeiro: Achiamé, 2012.

Políticas educacionais: o projeto neoliberal em debate. Embu das Artes: Alexa Cultural, 2007.

MITCHELL, P. R.; SCHOEFFEL, J. Para entender o poder. O melhor de Noam Chomsky. Tradução de Eduardo Francisco Alves. Rio de Janeiro: Bertrand Brasil, 2005. 